\title{
Hedef Programlama ile Nöbet Çizelgeleme Probleminin Çözümü
}

\author{
Fatih Mehmet ÜNAL ${ }^{1}$ ve Tamer EREN ${ }^{2 *}$ \\ ${ }^{1}$ Cumhurbaşkanlığı Muhafız Alayı, Tören Tabur Komutanlığı, 06680, Çankaya, Ankara \\ ${ }^{2 *}$ Endüstri Mühendisliği Bölümü, Mühendislik Fakültesi, Kırıkkale Üniversitesi, 71450, Kırıkkale
}

Geliş Tarihi: 2016-01-19 Kabul Tarihi: 2016-04-01

\section{$\ddot{O} z$}

Nöbet çizelgeleme birçok üretim ve hizmet sektöründe kullanılmaktadır. Nöbet çizelgeleme yapılırken birçok kritere dikkat edilmesi ve nöbet tutacak personelin memnuniyetinin ayn anda sağlanmak istenmesi problemi daha karıșık hale getirebilmektedir. Bu çalışmada hizmet sektöründeki bir devlet kurumunda nöbet çizelgeleme problemi ele alınmıştır. Ele alınan problemde nöbet tutan personelin istekleri göz önüne alınarak ağırlıklı hedef programlama modeli geliştirilmiştir. Problemin çözümleri GAMS 22.5 paket programı ile gerçekleştirilmiştir.

Anahtar Kelimeler: Nöbet Çizelgeleme, Hedef Programlama, Çok Amaçlı Karar Verme.

\section{The Solution of Shift Scheduling Problem by Using Goal Programming}

\author{
Fatih Mehmet ÜNAL ${ }^{1}$ ve Tamer EREN ${ }^{2 *}$ \\ ${ }^{1}$ Cumhurbaşkanlığı Muhafız Alayı, Tören Tabur Komutanlığı, 06680, Çankaya, Ankara \\ ${ }^{2 *}$ Endüstri Mühendisliği Bölümü, Mühendislik Fakültesi, Kırıkkale Üniversitesi, 71450, Kırıkkale
}

\begin{abstract}
Shift scheduling is being used in various production and service sectors. It makes it more complicated to consider many aspects while doing shift scheduling and also taking into account the gladness of the shift scheduling. In this study also we are looking at shift scheduling problem of a service sector which belongs to a government association. In this particular problem, goal programming model is developed by considering the wishes of shift scheduling. The solution for the problem is acquired by GAMS 22.5 packet program.
\end{abstract}

Keywords: Shift Scheduling, Goal Programming, Multiple-Objective Decision Making.

\section{Giriş}

Personel çizelgeleme, hastane, havayolu, otel, telekomünikasyon merkezi, çağrı merkezi ve güvenlik sektörü gibi geniş çaplı alanlarda sıkça uygulanmaktadır. $\mathrm{Bu}$ tarz hizmet sektörlerinde genellikle yıl boyunca 7 gün 24 saat hizmet esas1 bulunmaktadır. Bunun için kurumlar personelinden 24 saat esasına göre hizmet istemekte ve personellerini kurumlarının özel ihtiyaçlarına göre çizelgelemektedirler. Çizelgeler günlük, haftalık, aylık gibi birçok şekilde düzenlenmektedir.

Personel çizelgeleme, yasal düzenlemelere ve kurumların amaçlarına uygun kısıtların sağlanmasının yanında, personel isteklerini karşılayarak onların memnuniyetlerini arttıracak aynı zamanda hizmet alanların ihtiyaçlarını karşılayacak işgücü planlarını ve çizelgeleri oluşturmaktır.

Günümüzdeki personel çizelgeleme problemleri, Edie [1] ve Dantzig [2]'nin 1950'lerde tanımladığ problemlerden çok farklıdır. Personel çizelgeleme problemlerinde çalışanların ihtiyaçlarını karşılamanın önemi artmaktadır. Kurumlar personel çizelgeleme yaparken çalışanların isteklerini dikkate almaktadırlar [3].

Personel çizelgelemede temel amaç; kaynaklardan etkili bir biçimde yararlanmak, dengeli iş yükü dağılımını sağlamak ve mümkün olduğunca bireysel istekleri karşılamaktır. İyi bir çizelge, çalışanların ve hizmet alanların ihtiyaçları ile kurumun görevlerini dengeler, gerekli olan iş yükünü personele adaletli ve uygun bir şekilde planlar.

*Corresponding author: Endüstri Mühendisliği Bölümü, Mühendislik Fakültesi, Kırıkkale Üniversitesi, 71450, Kırıkkale, tamereren@gmail.com 
İşücü, vardiya ve görevlere atanırken çalışan tercihlerine dikkat etmek önemlidir. Çünkü çalışanların tercihlerine dikkat edildiği zaman, personel daha verimli olmakta ve bunun sonucunda hizmet kalitesi artmaktadır. İşletmeler, işgücü yoğunluğunun fazla olduğu hizmet sektörünün artan önemi sonucunda, işgücünün etkin kullanımına daha fazla önem vermeye başlamışlardır [4].

Bu çalışmada, bir devlet kurumunda aylık dönemler halinde nöbet çizelgeleme problemi için ağırlıklı hedef programlama modeli önerilmiştir. Önerilen modelin en önemli özelliği, personele görevi gereği zorunlu olarak tutacağı nöbetlerini seçme imkânı tanımasıdır. Ancak bu hedef aynı zamanda her personele eşit sayıda ve ağırlıkta nöbet planlamak ile bu nöbetlerin mümkün olduğunca aralıklı olmasını sağlamak hedefleri ile birlikte değerlendirilmektedir. Yani personel nöbet tutmak istediği günleri belirtmekte olup, kurum ve diğer çalışanlar zarara uğratılmayacak şekilde, personel mümkün olduğunca kendi belirttiği günlere nöbetçi olarak atanmaktadır.

Çalışmanın planı şu şekildedir: İkinci bölümde, personel çizelgeleme üzerine literatürde yapılmış çalışmalar sunulmuştur. Üçüncü bölümde, nöbet çizelgeleme problemlerinin özelliklerinden bahsedilmiştir. Dördüncü bölümde, problemin özellikleri ve çözümü için önerilen hedef programlama modeli üzerinde durulmuştur. Beşinci bölümde örnek uygulama yapılmıştır. Son bölüm olan altıncı bölümde ise yapılan çalışma için genel bir değerlendirme yapılmış, ileride yapılabilecek çalışmalar konusunda önerilerde bulunulmuştur.

\section{Literatürde Yapılan Çalışmalar}

Personel çizelgeleme çok zahmetli ve vakit harcayan bir iştir. Çizelgeleme yapılırken birçok zorunlu kisit ile personelin ve hizmet alanların memnuniyetinin aynı anda sağlanmak istenmesi problemi daha karışık hale getirebilmektedir. Genellikle el ile hazırlanan ve göz önünde bulundurulacak çok sayıda kısıtın olmasından dolayı hazırlanması uzun ve zahmetli olan çizelgelerin, uygulanan yenilikçi sistematikler sayesinde, çok kısa sürelerde ve daha etkin şekilde oluşturulması sağlanabilmektedir. Gün geçtikçe kurumlar arasında yenilikçi sistematiklerin uygulanması artmaktadır.

Ernst vd. [5] yaptıkları çalışmada personel çizelgeleme problemi ile ilgili yapılan çalışmaları, uygulama alanlarına göre sinıflandırarak, bunların modellerini ve çözüm algoritmalarını incelemişlerdir. Bergh vd. [3] yapmış oldukları çalışmada personel çizelgeleme problemleri üzerine yapılan çalışmaları incelemişlerdir. Öncelikle daha önce yapılan inceleme makalelerini inceleyerek sinıflandırma yöntemlerini oluşturmuşlardır. Daha sonra 300'e yakın çalışmayı inceleyerek, oluşturmuş oldukları sinıflandırma yöntemlerine göre bu çalışmaları sınıflandırmışlardır.

Ünal [6] hizmet sektöründeki bir devlet kurumunda, yasal ve kurumsal hedeflerin yanında personel isteklerini de ön plana alarak, hedef programlama ve analitik hiyerarşi proses yöntemini birlikte kullanarak personel çizelgeleme problemini incelemiştir. Azaies ve Al-Sharif [7] yaptıkları çalışmada hemşire çizelgeleme problemini ele almışlardır. Burada el ile yapılan çizelgeler yerine 0-1 hedef programlama yaklaşımı ile bir model geliştirmişlerdir. Topaloğlu [8] yaptığ çalışmada hedef programlama ile acil tıp çalışanları çizelgeleme problemini ele almıştır. Chu [9] yaptığı çalışmada hedef programlama ile Hong Kong uluslararası havaalanının bir biriminde personel çizelgeleme problemini incelemiştir. Bağ vd. [10] çalışmalarında hemşire çizelgeleme problemini incelemişlerdir. Problemi çözmek için 0-1 hedef programlama yöntemini kullanmışlardır. Hedeflerinin ağırlıklarının belirlenmesi için ise analitik ağ proses yöntemini kullanmışlardır. HungTsu vd. [11] hedef programlama ile Güney Tayvan'da bir mağazada personel çizelgeleme problemini incelemişlerdir. Bektur ve Hasgül [4] geliştirmiş olduğu hedef programlama modeli ile bir restoranda personel çizelgelenme problemini incelemişlerdir. Louly [12] yaptığı çalı̧̧mada bir telekomünikasyon merkezinde vardiya çizelgeleme problemi için hedef programlama modeli geliştirmiştir. Labadi vd. [13] Banka Bilgi Teknolojileri personeli çizelgelemesi için çok amaçlı hedef programlama modeli geliştirmişlerdir. Todovic vd. [14] çalışmalarında hedef programlama modeli ile Bosna Hersek'teki bir polis karakolunda, polis memurların çizelgelenmesini incelemişlerdir. Horn vd. [15] yaptıkları çalışmada Avustralya Kraliyet Donanmasinda karakol botları ve mürettebatını çizelgeleme problemini incelemişlerdir. Li vd. [16] birçok zorunlu ve yumuşak kısıttan oluşan hedef programlama ile sezgisel yöntemleri bir arada kullanarak, melez bir yaklaşımla personel çizelgelemesi yapmışlardır.

Bard vd. [17] yaptıkları çalışmada Amerika Birleşik Devletleri posta servisinde tur planlama problemini ele almışlar ve problemi tamsayılı doğrusal programlama olarak formüle etmişlerdir. Çetin vd. [18] yaptıkları çalışmada tamsayılı programlama ile uçuş ekibi planlaması üzerinde durmuşlardır. Ekip planlamanın iki aşaması olan, ekip eşleştirme ve ekip atama problemlerini bütünleşik bir yapıda ele almışlardır. Öztürkoğlu ve Çalışan [19] çalışmalarında hemşire çizelgeleme problemi için tam sayılı matematiksel bir model oluşturmuşlardır. Oluşturulan modelde, klasik çizelgeleme 
modellerinin aksine hemşirelerin işe başlama saatlerine esneklik getirilmiştir. Sungur [20] yaptığı çalışmada bir güzellik salonunda, tur çizelgeleme problemi için karma tamsayılı programlama modeli geliştirmiş̧ir. Fırat ve Hurkens [21] yaptıkları çalışmada karışık tamsayılı programlama ile farklı yetenek isteyen işlere uygun yetenekli teknisyenleri atamışlardır.

Güneş vd. [22] yaptıkları çalışmada, genetik algoritma kullanılarak bir yazılım geliştirmiş ve çok zaman alan askeri nöbet çizelgesi hazırlama işlemlerinin; harcanan süre ve sağlanan doğruluk yönü ile en iyilenmesini amaçlamışlardır. Tsai ve Li [23] yapmış oldukları çalışmada genetik algoritma ile hemşire çizelgeleme problemini ele almışlardır. Zolfaghari vd. [24] yapmış oldukları çalışmada perakende sektöründe, personel çizelgeleme problemi için genetik algoritma modeli geliştirmişlerdir.

Görüldüğü üzere literatürde personel ve vardiya özelliklerine göre birçok farklı çizelgeleme problemi ele alınmıştır. Oluşturulan çizelgeleme modellerinin, kurumun amaçlarının yanında personel isteklerini ve hizmet alanlarin memnuniyetini aynı anda sağlaması gerektiği görülmekte olup incelenen problemlerde personel memnuniyeti açısından birçok isteğin sağlandığı görülmektedir. Ancak personelin kendi istek belirttiği günlere nöbetçi olarak atanmasını amaçlayan bir çalışmaya rastlanmamıştır. Aşağıda önerdiğimiz ağırlıklı hedef programlama modeli, personele görevi gereği zorunlu olarak tutacağ 1 nöbetlerini, kurumu ve diğer çalışanları zarara uğratmadan imkânlar dâhilinde seçme imkânı tanımaktadır. Aynı zamanda tüm personele kıdem seviyelerine göre eşit sayıda ve ağırlıkta nöbet planlamayı ve planlanan bu nöbetlerin, personelin yorulmaması için mümkün olduğunca aralıklı olmasını amaçlamaktadır.

\section{Nöbet Çizelgeleme Probleminin Özellikleri}

$\mathrm{Bu}$ çalışmada bir devlet kurumunda personel çizelgeleme problemi incelenmiştir. Kurum, görevleri kapsamında çalışanlarından her gün bir kişiyi, normal mesai saatleri dışında nöbetçi olarak görevlendirmektedir. Hâlihazır durumda nöbet çizelgeleri aylık dönemler halinde, görevlendirilen bir personel tarafindan el ile hazırlanmaktadır. Görevlendirilen personel bulunulan aylık dönemin son haftası, çizelgeleme yapılacak bir sonraki dönem için personel mazeretlerini toplamakta ve çizelgeleri oluşturmaktadır.

Çizelgeler oluşturulurken personel mazeretlerine ve kıdem seviyelerine dikkat edilmekte ve bütün personele hafta sonu ve hafta içi dağılımı adil olmak üzere eşit sayıda nöbet yazılmak istenmektedir. Ancak bütün günlerin aynı ağırlıkta olmaması ve bazı ayların gün olarak fazla olmasından kaynaklı olarak, bu hedefler tam olarak sağlanamayabilmektedir. Böyle durumlarda her personele eşit sayıda ve ağırlıkta nöbet yazıldıktan sonra artık günler öncelikle kıdemsiz personelden kıdemliye doğru yazılmak istenmektedir. Ayrıca personelin gün aşırı veya yakın tarihli nöbetler tutması personeli olumsuz olarak etkilemekte ve nöbetlerin arasının gün olarak uzun olmasının istenmesi problemi daha karmaşık hale getirmektedir. $\mathrm{Bu}$ gibi etkenler sonucu el ile hazırlanan çizelgelerin hazırlanma süresi artmakta ve personel isteklerini tam olarak karşılayan çizelgeler hazırlanamamaktadır.

Ayrıca çalışanlar birtakım özel sebeplerinden dolayı ayın belirli günlerinde nöbet tutmaya istekli olabiliyorlar. Yani görevi gereği zorunlu olarak tutacağı nöbeti, kurumu ve diğer çalışanları zarara uğratmadan imkânlar dâhilinde kendi belirttiği günlerde tutmak isteyebilmektedirler.

Matematiksel bir model ile nöbet çizelgelerinin hazırlanma süresinin azalacağı ve istenilen seviyede çizelgelerin hazırlanacağı öngörülmüştür. Fakat oluşturulacak olan model ile kurumun zorunlu kısıtlarının sağlanmasının yanında tüm personele 1 aylık dönemde eşit sayıda ve ağırlıkta nöbet yazılması ile örtüşen personel istekleri sonucu isteklerin tam olarak sağlanamayacağ değerlendirilmiştir. Bu sebepten dolayı problemin çözümü için hedef programlama yöntemi seçilmiştir.

\section{Geliştirilen Hedef Programlama Modeli}

Zorunlu ve gevşek kısıtlardan oluşan hedef programlama modeli ile personel nöbetlere atanmaktadır. Amaç fonksiyonu zorunlu kısıtların sağlanmasının yanında kıdem seviyelerine göre gevşek kısıtların en küçüklenmesi ve nöbet tutmak için istekli olunan günlere nöbet yazılmasının en büyüklenmesidir. Problemde kullanılan indisler, parametreler, karar değişkenleri ile matematiksel model ve hedefler aşağıda verilmiştir.

\subsection{Modelde Kullanılan İndisler}

i $\rightarrow$ Personel,

$i=1,2, \ldots, 10$

ic $\rightarrow$ Personel,

ic $\in \mathrm{i}$

j $\rightarrow$ Çizelgeleme yapılan günler,

$l \rightarrow$ Hedefler,

$$
\mathrm{j}=1,2, \ldots, 30
$$$$
l=1,2,3,41,42 \ldots, 48
$$

\subsection{Modelde Kullanılan Parametreler}


$\mathrm{k}_{\mathrm{i}} \rightarrow i$. personelin k1dem katsayıs1,

$i=1,2, \ldots, 10$

$g_{j} \rightarrow j$. günün ağırlığg,

$\mathrm{W}_{\mathrm{l}} \rightarrow l$. hedefin ağırlı̆ 1 ,

$$
\mathrm{j}=1,2, \ldots, 30
$$

$$
l=1,2,3,41,42 \ldots, 48
$$
$M_{i j}=\left\{\begin{array}{c}1, \text { i. personel j. gün mazeret belirtmiş } \\ 0, \mathrm{~d} . \mathrm{d} .\end{array}\right.$

$\mathrm{i}=1,2, \ldots, 10$

$$
\mathrm{j}=1,2, \ldots, 30
$$

$T_{i j}=\{1$, i. pers. j. gün nöbet tutmak için istekli

$$
0, \text { d. d. }
$$

$$
\begin{aligned}
& i=1,2, \ldots, 10 \\
& j=1,2, \ldots, 30
\end{aligned}
$$

\subsection{Modelde Kullanılan Karar Değişkenleri}

$$
\begin{aligned}
& x_{i j}=\left\{\begin{array}{c}
1, \text { i. personel j.gün nöbetçi } \\
0, \text { d. d. }
\end{array}\right. \\
& \mathrm{i}=1,2, \ldots, 10 \\
& \mathrm{j}=1,2, \ldots, 30
\end{aligned}
$$

$\mathrm{v}_{\mathrm{i}, \mathrm{ic}}^{+1}=1$. Gevşek kısıtın pozitif yönde sapma değişkeni $\quad \mathrm{i}=1,2, \ldots, 10$

$\mathrm{v}_{\mathrm{i}, \mathrm{ic}}^{-1}=1$. Gevşek kısıtın negatif yönde sapma değişkeni $\quad \mathrm{i}=1,2, \ldots, 10$

$\mathrm{v}_{\mathrm{i}, \mathrm{ic}}^{+2}=2$. Gevşek kısıtın pozitif yönde sapma değişkeni $\quad \mathrm{i}=1,2, \ldots, 10$

$\mathrm{v}_{\mathrm{i}, \mathrm{ic}}^{-2}=2$. Gevşek kısıtın negatif yönde sapma değişkeni $\quad \mathrm{i}=1,2, \ldots, 10$

$\mathrm{v}_{\mathrm{i}}^{+3}=3$. Gevşek kısıtın pozitif yönde sapma değişkeni $\quad \mathrm{i}=1,2, \ldots, 10$

$v_{i}^{-3}=3$. Gevşek kısıtın negatif yönde sapma değişkeni $\quad \mathrm{i}=1,2, \ldots, 10$

$\mathrm{v}_{\mathrm{i}, \mathrm{j}}^{+4 \mathrm{a}}=4$. Gevşek kısıtın pozitif yönde sapma değişkeni

$$
\mathrm{a}=1,2, \ldots, 8
$$

$\mathrm{v}_{\mathrm{i}, \mathrm{j}}^{-4 \mathrm{a}}=4$. Gevşek kısıtın negatif yönde sapma değişkeni,

$$
\mathrm{i}=1,2, \ldots, 10
$$

$$
\mathrm{a}=1,2, \ldots, 8
$$

Kisitlar

$$
\begin{array}{lr}
x_{i, j}+x_{i, j+1}+x_{i, j+2}-v_{i, j}^{+41}+v_{i, j}^{-41}=1, & i=1,2, \ldots, 10, j=1,2, \ldots, 28 \\
x_{i, j}+x_{i, j+1}+x_{i, j+2}+x_{i, j+3}-v_{i, j}^{+42}+v_{i, j}^{-42}=1, & i=1,2, \ldots, 10, j=1,2, \ldots, 27 \\
x_{i, j}+x_{i, j+1}+x_{i, j+2}+x_{i, j+3}+x_{i, j+4}-v_{i, j}^{+43}+v_{i, j}^{-43}=1, & i=1,2, \ldots, 10, j=1,2, \ldots, 26 \\
x_{i, j}+x_{i, j+1}+x_{i, j+2}+x_{i, j+3}+x_{i, j+4}+x_{i, j+5}-v_{i, j}^{+44}+v_{i, j}^{-44}=1, & i=1,2, \ldots, 10, \\
x_{i, j}+x_{i, j+1}+x_{i, j+2}+x_{i, j+3}+x_{i, j+4}+x_{i, j+5}+x_{i, j+6}-v_{i, j}^{+45}+v_{i, j}^{-45}=1, & i=1,2, \ldots, 10, j=1,2, \ldots, 24 \\
x_{i, j}+x_{i, j+1}+x_{i, j+2}+x_{i, j+3}+x_{i, j+4}+x_{i, j+5}+x_{i, j+6}+x_{i, j+7}-v_{i, j}^{+46}+v_{i, j}^{-46}=1,
\end{array}
$$

(1) numaralı kısıt her gün sadece bir personelin nöbetçi olarak atanmasını sağlamaktadır.

$x_{i, j}+x_{i, j+1} \leq 1, i=1,2, \ldots, 10, j=1,2, \ldots, 29$

(2) numaralı kısıt her personel için ardışık nöbet yazılmasını engellemektedir. Modelde zorunlu olarak ardışık nöbetlere izin verilmemektedir.

$$
\sum_{i=1}^{10} \sum_{j=1}^{30} x_{i, j} \times M_{i, j}=0,(3)
$$

(3) numaralı kısıt ise personelin mazeret belirttiği günlere nöbet yazılmasını engellemektedir.

$$
\begin{aligned}
& \sum_{j=1}^{30} x_{i, j}-\sum_{j=1}^{30} x_{i c, j}-v_{i, i c}^{+1}+v_{i, i c}^{-1}=0, \\
& i=1,2, \ldots, 9, i c=(i+1), \ldots, 10,(4) \\
& \sum_{j=1}^{30} x_{i, j} \times g_{j}-\sum_{j=1}^{30} x_{i c, j} \times g_{j}-v_{i, i c}^{+2}+v_{i, i c}^{-2}=0 \\
& , i=1,2, \ldots, 9, i c=(i+1), \ldots, 10,(5) \\
& \sum_{j=1}^{30} x_{i, j} \times T_{i, j}-v_{i}^{+3}+v_{i}^{-3}=0, i=1,2, \ldots, 10,(6)
\end{aligned}
$$

Kisit (4), (5), (6) ve (7-14) gevşek kisitlardır. Kısıt (4) ile her personel ikili olarak karşılaştırılarak aylık toplam nöbet sayıları arasındaki fark bulunmaktadir. Kisit (5) ile yine her personel ikili olarak karşılaştırılarak aylık toplam nöbet ağırlıkları arasındaki fark bulunmaktadır. Her 2 kısıtta da her personel kıdem olarak kendisinden sonra gelen her personelle karşılaştırılmaktadır. Böylece her personelin gereksiz yere 2 defa kiyaslanması engellenmiştir. Pozitif sapmalar kıdemli personelin fazla nöbet sayısını $\left(v_{i, i c}^{+1}\right)$ ve fazla nöbet ağırlığını $\left(v_{i, i c}^{+2}\right)$, negatif sapmalar ise k1demsiz personelin fazla nöbet sayısını $\left(v_{i, i c}^{-1}\right)$ ve fazla nöbet ağırlığını $\left(\mathrm{v}_{\mathrm{i}, \mathrm{ic}}^{-2}\right)$ göstermektedir. Kısıt (6) her personelin nöbet tutmak için istek belirttiği günlere, kaç adet nöbetinin yazıldığını tespit etmek için geliştirilmiştir. Buradaki pozitif sapmalar $\left(\mathrm{v}_{\mathrm{i}}^{+3}\right)$ personelin kaç adet nöbetinin personelin istek belirttiği günlere planlandığını göstermektedir. 


$$
\begin{gathered}
i=1,2, \ldots, 10, j=1,2, \ldots, 23 \\
x_{i, j}+x_{i, j+1}+x_{i, j+2}+x_{i, j+3}+x_{i, j+4}+x_{i, j+5}+x_{i, j+6}+x_{i, j+7}+x_{i, j+8}-v_{i, j}^{+47}+v_{i, j}^{-47}=1, \\
i=1,2, \ldots, 10, j=1,2, \ldots, 22 \\
x_{i, j}+x_{i, j+1}+x_{i, j+2}+x_{i, j+3}+x_{i, j+4}+x_{i, j+5}+x_{i, j+6}+x_{i, j+7}+x_{i, j+8}+x_{i, j+9}-v_{i, j}^{+48}+v_{i, j}^{-48}=1, \\
i=1,2, \ldots, 10, j=1,2, \ldots, 21
\end{gathered}
$$

Kısıt (7-14) serisi personel nöbetlerinin ne kadar ara ile yazıldığını kontrol etmektedir. Her personelin; kısıt (7) ile her ardışık 3 günde 1'den fazla nöbetinin olup olmadığı, kısıt (8) ile her ardışık 4 günde 1'den fazla nöbetinin olup olmadığı, kısıt (9) ile her ardışık 5 günde 1 'den fazla nöbetinin olup olmadığı, kısıt (10) ile her ardışık 6 günde 1 'den fazla nöbetinin olup olmadığı, kısit (11) ile her ardışı 7 günde 1 'den fazla nöbetinin olup olmadığı, kısıt (12) ile her ardışık 8 günde 1'den fazla nöbetinin olup olmadığı, kısit (13) ile her ardışı 9 günde 1 'den fazla nöbetinin olup olmadığı, kısıt (14) ile her ardışı 10 günde 1'den fazla nöbetinin olup olmadığı kontrol edilmektedir.

$$
x_{i, j} \in\{0,1\} \quad i=1,2, \ldots, 10, j=1,2, \ldots, 30
$$

(15) numaralı kısıt ile $x_{i, j}$ değişkeninin 0 veya 1 değerlerinden herhangi birini alabileceği belirtilmiştir.

$$
\begin{aligned}
& v_{i, i c}^{+1}, v_{i, i c}^{-1}, v_{i, i c}^{+2}, v_{i, i c}^{-2}, v_{i}^{+3}, v_{i}^{-3}, v_{i, j}^{+41}, v_{i, j}^{-41}, v_{i, j}^{+42}, v_{i, j}^{-42}, v_{i, j}^{+43}, v_{i, j}^{-43} v_{i, j}^{+44}, v_{i, j}^{-44}, v_{i, j}^{+45}, v_{i, j}^{-45}, \\
& v_{i, j}^{+46}, v_{i, j}^{-46}, v_{i, j}^{+47}, v_{i, j}^{-47}, v_{i, j}^{+48}, v_{i, j}^{-48} \geq 0
\end{aligned}
$$

Son olarak kısıt (16) ise ilgili karar değişkenlerinin 0'a büyük veya eşit olabileceğini göstermektedir.

\subsection{Hedefler}

Hedef 1: Her personele eşit sayıda nöbet yazilmalıdır.

$W_{1} \times\left(\sum_{i=1}^{9} \sum_{i c=i+1}^{10} v_{i, i c}^{+1} \times k_{i}+\sum_{i=1}^{9} \sum_{i c=i+1}^{10} v_{i, i c}^{-1} \times k_{i c}\right)$,

Denklem (17), kısıt (4)'ün sapmalarını en küçüklemek için geliştirilmiştir. Yani her personelin aylık toplam nöbet sayısı eşitlenmek istenmektedir. Ancak farklı aylarda toplam gün sayısının, toplam personel sayısının tam katları olmayan dönemler ile karşılaşılabilir. Böyle durumlarda her personelin toplam nöbet sayısını eşitlememiz mümkün olmayacaktır. Her personelin toplam nöbet sayısını eşitleyemediğimizde artık nöbetlerin öncelikle kıdemsiz personelden kıdemliye doğru yazılması için pozitif sapmalar kıdemli personelin kıdem katsayısı, negatif sapmalar ise kıdemsiz personelin kıdem katsayısı ile çarpılmıştır.

Hedef 2: Her personelin toplam nöbet ağırlığı eşit olmalıdır.

$W_{2} \times\left(\sum_{i=1}^{9} \sum_{i c=i+1}^{10} v_{i, i c}^{+2} \times k_{i}+\sum_{i=1}^{9} \sum_{i c=i+1}^{10} v_{i, i c}^{-2} \times k_{i c}\right)$,

Denklem (18), kısıt (5)'in sapmalarını en küçüklemek için geliştirilmiştir. Burada amaç her personele toplamda eşit ağırlıkta nöbet atayabilmektir. Ancak her günün ağırlığının aynı olmaması kaynaklı olarak her personelin toplam nöbet ağırlığını eşitleyememe durumumuz oluşabilmektedir. Böyle durumlarda toplam nöbet ağırlığının öncelikle kıdemli personelden kıdemsize doğru artması için pozitif sapmalar kıdemli personelin k1dem katsayısı, negatif sapmalar ise kıdemsiz personelin kıdem katsayısı ile çarpılmıştır.

Hedef 3: Her personelin nöbetleri, nöbet tutmak için istek belirttiği günlere planlanmalıdır.

$W_{3} \times\left(\sum_{i=1}^{10} v_{i}^{+3} \times k_{i}\right)$,

Denklem (19), kısıt (6)'nın sapmalarını en büyüklenmek için geliştirilmiştir. Buradaki her bir $v_{i}^{+3}$ değeri i. personelin kaç tane nöbetinin, personelin nöbet tutmak için istek belirttiği günlere atandığını göstermektedir. Ayrıca $v_{i}^{+3}$ değeri ilgili personelin kıdem katsayısıyla çarpılarak öncelikle k1demli personelden itibaren, kıdemsiz personele doğru istekler karşılanmaktadır.

Hedef 4: Her personelin nöbetler arası mesafesi mümkün olduğunca gün olarak uzun olmalıdır.

$$
\begin{aligned}
& W_{41} \times\left(\sum_{i=1}^{10} \sum_{j=1}^{28} v_{i, j}^{+41} \times k_{i}\right), \\
& W_{42} \times\left(\sum_{i=1}^{10} \sum_{j=1}^{27} v_{i, j}^{+42} \times k_{i}\right),
\end{aligned}
$$




$$
\begin{aligned}
& W_{43} \times\left(\sum_{i=1}^{10} \sum_{j=1}^{26} v_{i, j}^{+43} \times k_{i}\right),(21) \\
& W_{44} \times\left(\sum_{i=1}^{10} \sum_{j=1}^{25} v_{i, j}^{+44} \times k_{i}\right),(22) \\
& W_{45} \times\left(\sum_{i=1}^{10} \sum_{j=1}^{24} v_{i, j}^{+45} \times k_{i}\right),(23) \\
& W_{46} \times\left(\sum_{i=1}^{10} \sum_{j=1}^{23} v_{i, j}^{+46} \times k_{i}\right),(24) \\
& W_{47} \times\left(\sum_{i=1}^{10} \sum_{j=1}^{22} v_{i, j}^{+47} \times k_{i}\right),(25)
\end{aligned}
$$

$$
W_{48} \times\left(\sum_{i=1}^{10} \sum_{j=1}^{21} v_{i, j}^{+48} \times k_{i}\right),(26)
$$

Denklem (20-27) serisi ile (7-14) serisi kısitların pozitif sapmaları en küçüklenmektedir. Bahse konu nöbet grubunda 10 personel olduğu için 1 aylık çizelgeleme döneminde her personele ortalama 3 nöbet düşmektedir. Bundan dolayı her personelin ortalama 10 günde 1 nöbet tutması hedeflenmiştir. Ancak bu hedefimizi tek kısit olarak (14) yazmamız halinde, ilgili gevşek kısıtının sağlanamaması durumunda 1 veya 2 gün gibi yakın aralıklı nöbetlerle karşllaşabilme durumumuz oluşabilmektedir. Bunun engellenmesi için bu kısıt kendi içinde kademelendirilmiş ve her personel için nöbetler arasının gün olarak mümkün olduğunca uzun olması sağlanmıştır.

\subsection{Amaç Fonksiyonu}

$$
\begin{aligned}
& \min =W_{1} \times\left(\sum_{i=1}^{9} \sum_{i c=i+1}^{10} v_{i, i c}^{+1} \times k_{i}+\sum_{i=1}^{9} \sum_{i c=i+1}^{10} v_{i, i c}^{-1} \times k_{i c}\right)+W_{2} \times\left(\sum_{i=1}^{9} \sum_{i c=i+1}^{10} v_{i, i c}^{+2} \times k_{i}+\sum_{i=1}^{9} \sum_{i c=i+1}^{10} v_{i, i c}^{-2} \times k_{i c}\right) \\
& -W_{3} \times\left(\sum_{i=1}^{10} v_{i}^{+3} \times k_{i}\right)+W_{41} \times\left(\sum_{i=1}^{10} \sum_{j=1}^{28} v_{i, j}^{+41} \times k_{i}\right)+W_{42} \times\left(\sum_{i=1}^{10} \sum_{j=1}^{27} v_{i, j}^{+42} \times k_{i}\right) \\
& +W_{43} \times\left(\sum_{i=1}^{10} \sum_{j=1}^{26} v_{i, j}^{+43} \times k_{i}\right)+W_{44} \times\left(\sum_{i=1}^{10} \sum_{j=1}^{25} v_{i, j}^{+44} \times k_{i}\right)+W_{45} \times\left(\sum_{i=1}^{10} \sum_{j=1}^{24} v_{i, j}^{+45} \times k_{i}\right) \\
& +W_{46} \times\left(\sum_{i=1}^{10} \sum_{j=1}^{23} v_{i, j}^{+46} \times k_{i}\right)+W_{47} \times\left(\sum_{i=1}^{10} \sum_{j=1}^{22} v_{i, j}^{+47} \times k_{i}\right)+W_{48} \times\left(\sum_{i=1}^{10} \sum_{j=1}^{21} v_{i, j}^{+48} \times k_{i}\right)
\end{aligned}
$$

Amaç fonksiyonumuz (28), gevşek kısıtlar olan (4), (5) ve (7-14)'ün sapmalarının kıdem seviyelerine göre en küçüklenmesi ile (6) numaralı kısıtların pozitif sapmalarının kıdem seviyelerine göre en büyüklenmesidir.

\subsection{Hedef Ağırlıklarının Belirlenmesi}

Hedeflerin ağırlık değerleri belirlerken öncelikle 4. Hedefin kendi içerisinde kademelendirildiği için bu hedefimizden başlamamız doğru olacaktır. Burada en iyi senaryonun personele 10 günde bir nöbet yazılması olduğundan bu hedefimizin ağırlığ $W_{48}=1$ olarak kabul edilmiştir. Bu hedefin gerçekleşememesi halinde bir alt kademe olan personele 9 günde 2 nöbet yazılmaya çalışılmalıdır. Bundan dolayı bu hedefimizin değeri bir önceki hedefe göre 2 kat daha fazla bir ağırlığa sahip olduğu düşünülerek $W_{47}=2$ olarak kabul edilmiştir. Aynı düşünce ile $W_{46}=4, W_{45}=8$, $W_{44}=16, W_{43}=32, W_{42}=64$ ve son olarak en istenmeyen durum olan personele 3 günde 2 nöbet yazılması olan hedefin ağırlığ $W_{41}=128$ olarak belirlenmiştir.

Personele planlanacak olan nöbetlerin mümkün olduğunca personelin istek belirttiği günlere planlanmasını sağlayan 3. Hedefin, nöbetler arası mesafelerin mümkün olduğunca gün olarak uzun olmasını sağlayan 4. Hedeften daha büyük bir ağırlığa sahip olması gerektiği görülmektedir. Çünkü personel kendi isteği ile yakın tarihli nöbetler tutmak isteyebilir. Bundan dolayı 3 . Hedefin ağırlığı, 4. Hedefin son kademesinin ağırlığından 2 kat daha fazla öneme sahip olduğu düşünülerek $W_{3}=256$ olarak belirlenmiştir.

Diğer iki hedef, personel arasındaki nöbet adaletinin sağlanması için 3. ve 4. Hedefimizden daha büyük bir ağırlığa sahip olmalıdır. Burada en önemli hedef olarak, her personele eşit sayıda nöbet yazılması olan 1. Hedef belirlenmiştir. İkinci olarak da her personelin toplam nöbet ağırlığının eşitlenmesi olan 2. Hedef belirlenmiştir. Sonuç olarak 2. Hedefin ağırlığı 3. Hedefinin ağırlığından 2 kat daha fazla ağırlığa sahip olduğu düşünüldüğünden $W_{2}=512$ ve aynı ilişki 1 . ve 2 . Hedeflerin arasında da kurulduğunda $W_{1}=1024$ olarak belirlenmiştir. Belirlenen ağırlıklar toplu olarak Tablo 1.'de sunulmuştur. 
Tablo 1. Hedeflerin Ağırlıkları

\begin{tabular}{|l|c|c|c|c|c|c|c|c|c|c|c|}
\hline Hedef & $W_{1}$ & $W_{2}$ & $W_{3}$ & $W_{41}$ & $W_{42}$ & $W_{43}$ & $W_{44}$ & $W_{45}$ & $W_{46}$ & $W_{47}$ & $W_{48}$ \\
\hline Ağırlık & 1024 & 512 & 256 & 128 & 64 & 32 & 16 & 8 & 4 & 2 & 1 \\
\hline
\end{tabular}

\subsection{Gün Ağırlıklarının Belirlenmesi}

Hafta içi nöbetleri saat 17:00 ile ertesi sabah saat 08:00 arasını kapsamaktadır. Yani hafta içi tutulan bir nöbet 15 saat sürmektedir. Cuma günü nöbetleri ise saat 17:00'da başlamakta ve ertesi sabah 09:00'da son bulmaktadır. Bu nöbet 16 saatlik bir süreyi kapsamakta ve personelin ilgili hafta sonu tatilini kısıtlamaktadır. Hafta sonu nöbetleri ise sabah 09:00'da başlamakta ve ertesi sabah 09:00'da son bulmakta olup toplam 24 saat sürmektedir.

Görüldüğü üzere farklı günlerdeki nöbetlerin ağırlıkları aynı değildir. Bundan dolayı gün ağırlıkları, çalışanların ortak düşünceleri doğrultusunda, günlerin zorluk derecelerine göre birbiriyle karşılaştırılması sonucunda Tablo 2.'de gösterildiği gibi belirlenmiştir. Ayrıca ilgili nöbet döneminde hiçbir günün ağırlığının ay başladıktan sonra değişmediği varsayılmıştır.

Tablo 2. Gün Ağırlıkları

\begin{tabular}{|l|l|}
\hline Günler & A ğırlıkları \\
\hline Haftaiçi & 3 \\
\hline Cuma & 5 \\
\hline Cumartesi & 9 \\
\hline Pazar & 8 \\
\hline Resmi Bayram & 7 \\
\hline Dini Bayram & 10 \\
\hline
\end{tabular}

\subsection{Personel Kıdem Seviyelerinin Belirlenmesi}

Kurumda k1dem seviyeleri farklı toplam 10 personel çalışmaktadır. Modelde her personelin kıdem seviyesi, kurumda çalıştı̆̆ 1 toplam yıl olarak alınmış olup Tablo 3.'de sunulduğu gibidir.

Tablo 3. Personel Kıdem Seviyeleri

\begin{tabular}{|l|l|}
\hline Personel & Kidem Seviyesi \\
\hline 1,2 & 9 \\
\hline 3,4 & 8 \\
\hline 5,6 & 7 \\
\hline 7,8 & 6 \\
\hline 9,10 & 5 \\
\hline
\end{tabular}

Burada farklı çalışan özelliklerine göre değişik seviyelendirme yapılabilir. Personel sayısının ve kurumda çalışılan toplam yıl sayısının çok artması durumunda, seviyeler 2'şer veya 3'er yıllık dönemler olarak alınabilir. Ancak toplam nöbet dengesinin bozulmaması için çalışanların kıdem katsayıları arasındaki oranın 2'den küçük olması gerektiği unutulmamalıdır. Ayrıca İlgili nöbet döneminde hiçbir personelin nöbet grubundan ay başladıktan sonra çıkmadığı ve başka hiçbir personelin nöbet grubuna sonradan dâhil olmadığı, ayrıca hiçbir personelin kıdem seviyesinin ilgili dönem içerisinde değişmediği varsayılmıştır.

\section{5. Örnek Uygulama}

Aylık nöbet çizelgesi hazırlanırken ilk önce her personelden, ilgili nöbet dönemi için mazeretli olduğu günler istenmektedir. Çalışanlar her hangi bir sebepten dolayı mazeretli olarak nöbet tutamayacakları günleri bildirmektedirler. Tablo 4 'de sunulmuş olan excel sayfasına personelin mazeret durumları girilmektedir. $i$. çalışan $j$. gün mazeret belirtmiş ise Tablo 4'de sunulmuş olan personel mazeret çizelgesinde ilgili değişken 1 değerini almaktadır. Mazeret belirtilmeyen diğer günler ise 0 değerini almaktadır. Çizelgeleme yapılacak örnek ay için personel mazeretleri Tablo 4'de gösterildiği gibidir.

İkinci olarak her personelden nöbet tutmak için istekli olduğu günleri belirtmeleri istenmektedir. Tablo 5'te sunulmuş olan excel sayfasına personelin nöbet tutmak için istek belirttiği günler girilmektedir. $i$. çalışan $j$. gün nöbet tutmak için istek belirtmiş ise Tablo 5'te sunulmuş olan personel istek çizelgesinde ilgili değişken 1 değerini almaktadır. İstek belirtilmeyen diğer günler ise 0 değerini almaktadır. Personel istekleri Tablo 5'te gösterildiği gibidir.

Geliştirilen çok amaçlı ağırlıklı hedef programlama modeli GAMS 22.5 paket programında kodlanarak, 'Intel ${ }^{\circledR}$ Core $^{\mathrm{TM}}$ i3-380M' işlemcisi, 3 GB belleği olan Windows 8 işletim sistemine sahip bilgisayar ile çözülmüştür. Burada Tablo 4 ve Tablo 5 ile modelin çözümü için gerekli olan $M_{i j}$ ve $T_{i j}$ parametreleri personelden toplanmış olup; yapılan kodlamalar ile GAMS paket programınin bu parametreleri doğrudan tablolar halinde ilgili excel sayfalarından alması sağlanmıştır.

Tablo 6. personel mazeret ve isteklerinin de belirtildiği problemimizin optimal çözümüdür. Personel mazeretleri kırmızı, istekleri ise yeşil renk tonları ile gösterilmiştir. $i$. personelin $j$. gün nöbetçi olarak atanması halinde ilgili değişken ' $\mathrm{X}$ ' işareti ile belirtilmiştir. 
Tablo 4. Personel Mazeret Çizelgesi

\begin{tabular}{|c|c|c|c|c|c|c|c|c|c|c|c|c|c|c|c|c|c|c|c|c|c|c|c|c|c|c|c|c|c|}
\hline $\begin{array}{l}\text { Gün/ } \\
\text { Personel }\end{array}$ & - & $N$ & $m$ & $\nabla$ & in & ( ) & - & $\infty$ & $a$ & 은 & $=$ & 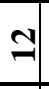 & 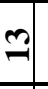 & $\Xi$ & 10 & $=$ & $=$ & $\stackrel{\infty}{\infty}$ & & $\vec{v}$ & ป & $\tilde{\sim}$ & 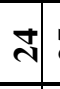 & 2 & ง & $\widehat{\sim}$ & $\underset{N}{\approx}$ & & ले| \\
\hline 1. Personel & & 1 & & & & & & 1 & 1 & & & & & & & & & & & & & & & & & \begin{tabular}{l|l|}
1 & 1 \\
\end{tabular} & 1 & & \\
\hline 2. Personel & & & & & 1 & & & & & & & 1 & & & & 1 & 1 & & & 1 & & & & & & & 1 & 1 & \\
\hline 3. Personel & & & & & & & & & & 1 & 1 & & & 1 & & & & & & & & & & & 1 & & & 1 & 1 \\
\hline 4. Personel & 1 & & & & & 1 & 1 & & & & & & & & 1 & & & 1 & 1 & & & & & & & & & & \\
\hline 5. Personel & & & & 1 & & & & & & & & & 1 & & & & & & & 1 & 1 & 1 & & & & & & & \\
\hline 6. Personel & & & 1 & & & & & & & & & & & & & 1 & 1 & 1 & & & & & 1 & 1 & & & & & \\
\hline 7. Personel & & & 1 & 1 & & & & 1 & & 1 & & & & & & & & & & & & & & 1 & & & & & \\
\hline 8. Personel & 1 & & & & & & & & & & 1 & & & & 1 & & & 1 & 1 & 1 & & & & & & & & & \\
\hline 9. Personel & & & & & & & & 1 & & & & 1 & & & & 1 & 1 & & 1 & 1 & & & & & & 1 & & & \\
\hline 10. Personel & & & & & 1 & 1 & & & & & & & & & & & & & & & 1 & & 1 & & 1 & & & & \\
\hline
\end{tabular}

Tablo 5. Personel İstek Listesi

\begin{tabular}{|c|c|c|c|c|c|c|c|c|c|c|c|c|c|c|c|c|c|c|c|c|c|c|c|c|c|c|c|c|}
\hline $\begin{array}{l}\text { Gün/ } \\
\text { Personel } \\
\end{array}$ & & N & $m$ & $\nabla$ & $n$ & e & & $\infty$ & $a$ & 을 & $\exists$ & บ? & $\Rightarrow=$ & $\pm !$ & $3=$ & $=5$ & 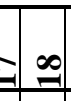 & 임 & తి & ㅊ: & ปู & בి d & in & ปి & 용 & 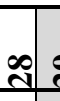 & टे & ल \\
\hline 1. Personel & & & & 1 & & & & & & & 1 & & & & 1 & & & & & & & 1 & 1 & & & & & \\
\hline 2. Personel & 1 & & & & & & & 1 & & & & & & & & & & 1 & 1 & & & & & & 1 & & & \\
\hline 3. Personel & & & & & 1 & & & & & & & 1 & 1 & 1 & 1 & & & & 1 & & 1 & & & & & & & \\
\hline 4. Personel & & & 1 & & & & & & & 1 & & & & & & & 1 & & & & 1 & & & & & & 1 & \\
\hline 5. Personel & 1 & & & & & & & 1 & & & & 1 & & & & & & 1 & & & & & & & 1 & & & \\
\hline 6. Personel & & & & & & 1 & & & & 1 & & & & 1 & 1 & & & & & & & & & 1 & & & 1 & \\
\hline 7. Personel & & & & 1 & & & & & 1 & & & & & 1 & & & & & & & & 1 & & & & & & 1 \\
\hline 8. Personel & & & 1 & & & & & & & & & 1 & & & 1 & 1 & & & & & 1 & 1 & & & & 1 & & \\
\hline 9. Personel & & & & & 1 & & & & 1 & & & & 1 & & & & & & & 1 & & & & & & & & 1 \\
\hline 10. Personel & & 1 & & & & & 1 & & & & & & & & & & 1 & & & & & & 1 & & & 1 & & \\
\hline
\end{tabular}

Tablo 6. Personel Nöbet Listesi

\begin{tabular}{|c|c|c|c|c|c|c|c|c|c|c|c|c|c|c|c|c|c|c|c|c|c|c|c|c|c|c|c|}
\hline $\begin{array}{l}\text { Gün/ } \\
\text { Personel }\end{array}$ & - & N & $m$ & $\nabla$ & $n$ & ๑) & & $\infty 0$ & 으 & $\exists$ & ㄴ? & 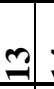 & $\pm !$ & $2=$ & 는 & 둥 & $\infty$ & 워 & $\vec{\Delta}$ & $\approx$ & $\approx$ & 志: & (2) & ㄴ: & 쇼 & ते & लે \\
\hline 1. Personel & & & & $\mathbf{X}$ & & & & & & & & & & & $\mathbf{X}$ & & & & & & & & $\mathbf{x}$ & & & & \\
\hline 2. Personel & & & & & & & & $\mathbf{X}$ & & & & & & & & & & $\mathbf{X}$ & & & & & & & $\mathbf{X}$ & & \\
\hline 3. Personel & & & & & $\mathbf{X}$ & & & & & & & $\mathbf{X}$ & & & & & & & & $\mathbf{X}$ & & & & & & & \\
\hline 4. Personel & & & & & & & & & $\mathbf{X}$ & & & & & & & & $\mathbf{X}$ & & & & & & & & & $\mathbf{X}$ & \\
\hline 5. Personel & $\mathbf{X}$ & & & & & & & & & & $\mathbf{X}$ & & & & & & $\mathbf{X}$ & $\mathrm{X}$ & & & & & & & & & \\
\hline 6. Personel & & & & & & $\mathbf{X}$ & & & & & & & & $\mathbf{X}$ & & & & & & & & & & $\mathbf{X}$ & & & \\
\hline 7. Personel & & & & & & & & $\mathrm{X}$ & & & & & $\mathbf{X}$ & & & & & & & & & $\mathbf{X}$ & & & & & \\
\hline 8. Personel & & & $\mathbf{X}$ & & & & & & & & & & & & & & & & & & $\mathbf{X}$ & & & & $\mathbf{X}$ & & \\
\hline 9. Personel & & & & & & & & & & $\mathbf{X}$ & & & & & & & & & $\mathbf{X}$ & & & & & & & & $\mathbf{X}$ \\
\hline 10. Personel & & $\mathbf{X}$ & & & & & $\mathbf{X}$ & & & & & & & & & $\mathbf{X}$ & & & & & & & & & & & \\
\hline
\end{tabular}


Burada modelin zorunlu kısıtların sağlandığ görülmektedir. Her gün bir kişi olacak şekilde ayın bütün günlerine nöbetçi atanmıştır. Hiçbir personele gün aşırı nöbet atanmamıştır. Yine ilgili çizelgede görüldüğü üzere amaç fonksiyonumuzla uyumlu olarak her personelin toplam nöbet sayısı eşitlenmiş olup, toplamda her personel 3 gün nöbetçi olarak atanmıştır.

Her günün ağırlığı eşit olmadığı için her personelin nöbet ağırlığı eşitlenememiştir. Fakat toplam nöbet ağırlıkları kıdem seviyelerine göre optimumdur. Her personele sadece 1 hafta sonu nöbeti atandığ 1 görülmekte olup en kıdemli personelin toplam nöbet ağırlığının en az olması model ile uyumludur.

Nöbetlerin \% 93 oranında personelin istek belirttiği günlere atandığı görülmektedir. İstek dışı atanan 2 nöbet olmakla birlikte 17 'nci günde zaten hiçbir personelin istek belirtmeği görülmektedir. Burada istek dışı nöbetlerin öncelikle kıdemsiz personele atanması model ile uyumludur.

Nöbetler arası mesafeler, mazeret ve istek günleri ile toplam nöbet sayısını ve ağırlığını eşitleme hedefleriyle birlikte değerlendirildiğgi için tüm personele 10 günde 1 nöbet yazılamamıștır. Ancak nöbetlerin genel olarak en az 7 gün arayla atandığı, sadece 3 nöbetin 5 gün aralıklı olarak atandığ görülmekte olup sonuçlar çalışanlar için çok iyi seviyede bulunmuştur.

\section{Sonuç ve Öneriler}

Yapılan çalışmada, 24 saat esasına göre hizmet veren bir devlet kurumda personel çizelgeleme problemi incelenmiştir. Literatürde personel çizelgeleme üzerine birçok çalışma yapılmıştır. Ancak yasal ve kurumsal kısitların sağlanmasının yanında, çalışanlara kıdem durumlarına göre eşit sayıda ve ağıllıkta nöbet yazılması hedeflenirken aynı zamanda ilgili nöbetlerin çalışanların istediği günlere planlamasını hedefleyen bir çalışmaya rastlanmamıştır.

Geliştirilen hedef programlama modeli ile personel, kıdem durumlarına göre eşit sayıda ve ağırlıkta olmak üzere, kurumu ve diğer çalışanları zarara uğratmadan, öncelikle kendi belirttiği günlere nöbetçi olarak atanmıştır. Aynı zamanda personeli yormamak için nöbetler arası mesafelerin, mümkün olduğunca fazla olması sağlanmıştır.

Model GAMS 22.5 paket programında kodlanarak, farklı kıdem seviyelerinde 10 personelin çalıştığ 1 bir kurumda uygulanmış olup, sonuçlar el ile hazırlanan çizelgelerle karşılaştırılmıştır. Öncelikle daha kısa sürelerde daha etkili çizelgelerin hazırlandığ 1 görülmüsştür. Oluşturulan nöbet çizelgesi ise çalışanlar için son derece tatminkâr bulunmuştur. Özellikle personelin görevi gereği zorunlu olarak tutacağı nöbetlerin, imkânlar dâhilinde personelin kendi belirttiği günlere atanması, personel üzerinde çok büyük olumlu etki yaratmıştır. Personelin moral ve motivasyonda artış gözlemlenmiş olup, bu durum kurumsal aidiyet duygusunun gelişmesinde de katkı sağlamıştır. İlerideki çalışmalarda model geliştirilerek iki aşamalı bir yapıya dönüştürülüp, her personelin yıllık toplam nöbet sayısının ve ağırlığının eşitlenmesi amaçlanabilir. Model yeni kısıtlar eklenerek veya mevcut kısıtlar değiştirilerek farklı kurumlar için kullanılabilir.

\section{Kaynaklar}

[1] L.C. Edie, "Traffic delays at toll booths", Operations Research, 2, 107-138 (1954).

[2] B.G. Dantzig, "Letter to the Editor-A Comment on Edie's 'Traffic Delays at Toll Booths'", Operations Research, 2, 339-341 (1954). [3] J.V. Bergh, J. Beliën, P. Bruecker, E. Demeulemeester, ve L. Boeck, "Personnel scheduling: A literature review", Eur. J. Oper. Res., 226, 367-385 (2013).

[4] G. Bektur ve S. Hasgül, "Kıdem seviyelerine göre işgücü çizelgeleme problemi: Hizmet sektöründe bir uygulama", Afyon Kocatepe Üniversitesi İktisadi ve İdari ve Bilimler Fakültesi Dergisi, 15, 385-402 (2013).

[5] A.T. Ernst, H. Jiang, M. Krishnamoorthy, ve D. Sier, "Staff scheduling and rostering: a review of applications, methods and models", Eur. J. Oper. Res., 153, 3-27 (2004).

[6] Ünal, F.M., Analitik Hiyerarşi Prosesi ve Hedef Programlama ile Nöbet Çizelgeleme Probleminin Çözümü, Yüksek Lisans Tezi, Kırıkkale Üniversitesi Fen Bilimleri Enstitüsü, Kırıkkale, 2015.

[7] M.N. Azaiez, ve S.S. Al-Sharif, "A 0-1 goal programming model for nurse scheduling", Computers and Operations Research, 32, 491-507 (2005).

[8] S. Topaloğlu, "A multi-objective programming model for scheduling emergency medicine residents", Computers and Industrial Engineering, 51, 375-388 (2006).

[9] S.C.K. Chu, "Generating, scheduling and rostering of shift crew-duties: Applications at the Hong Kong International Airport", Eur. J. Oper. Res., 177, 1764-1778 (2007).

[10] N. Bağ, N.M. Özdemir ve T. Eren, "0-1 Hedef Programlama ve ANP Yöntemi ile Hemşire Çizelgeleme Problemi Çözümü", International Journal of Engineering Research and Development, 4, 2-6 (2012).

[11] L. Hung-Tso, C. Yen-Ting, C. Tsung-Yu ve L. Yi-Chun, "Crew rostering with multiple goals: an empirical study", Computers and Industrial Engineering, 63, 483-493 (2012). 
[12] M.A. Louly, "A goal programming model for staff scheduling at a telecommunications center", Journal of Mathematical Modelling and Algorithms in Operations Research, 12, 167-178 (2013).

[13] M. Labidi, M. Mrad, A. Gharbi, ve M.A. Louly, "Scheduling IT Staff at a Bank: A Mathematical Programming Approach", The Scientific World Journal, Article ID 768374 (2014).

[14] D. Todovic, D. Makajic-Nikolic, M. Kostic-Stankovic ve M. Martic, "Police officer scheduling using goal programming", Policing: An International Journal of Police Strategies and Management, 38, 295-313 (2015).

[15] M. Horn, H. Jiang ve P. Kilby, "Scheduling patrol boats and crews for the Royal Australian Navy", Journal of the Operational Research Society, 58, 1284-1293 (2007).

[16] J. Li, E.K. Burke, T. Curtois, S. Petrovic ve Q. Rong, "The falling tide algorithm: a new multi-objective approach for complex workforce scheduling", Omega, 40, 283-293 (2012).

[17] J.F. Bard, C. Binici ve A.H. DeSilva, "Staff scheduling at the United States Postal Service", Comput. Oper. Res., 30, 745-771 (2003). [18] E.İ. Çetin, A. Kuruüzüm ve S. Irmak, "Ekip Çizelgeleme Probleminin Küme Bölme Modeli ile Çözümü", Havacılık ve Uzay Teknolojileri Dergisi, 3, 47-54 (2008).
[19] Y. Öztürkoğlu ve F. Çalışkan, "Hemşire Çizelgelemesinde Esnek Vardiya Planlaması ve Hastane Uygulaması", Dokuz Eylül Üniversitesi Sosyal Bilimler Enstitüsü Dergisi, 16, 115-133 (2014)

[20] B. Sungur, "Bir güzellik salonunun tur çizelgeleme problemi için karma tamsayılı hedef programlama modelinin geliştirilmesi", İstanbul Üniversitesi İşletme Fakültesi Dergisi, 37, 49-64 (2008).

[21] M. Firat ve C.A.J. Hurkens, "An improved MIP-based approach for a multi-skill workforce scheduling problem", Journal of Scheduling, 15, 363-380 (2011).

[22] A. Güneş, A. Kahvecioğlu ve H. Tuncel, "Askeri nöbet çizelgelerinin genetik algoritma kullanılarak en iyilenmesi", Elektrik-ElektronikBilgisayar Mühendisliği 11 'inci Ulusal Kongresi ve Fuar1, İstanbul, 470-474 (2005).

[23] C.C. Tsai ve S.H.A. Li, "A two-stage modeling with genetic algorithms for the nurse scheduling problem", Expert Systems with Applications, 36, 9506-9512, (2009).

[24] S. Zolfaghari, V. Quan, A. El-Bouri ve M. Khashayardoust, "Application of a genetic algorithm to staff scheduling in retail sector", International Journal of Industrial and Systems Engineering, 5, 20-47 (2010). 